\title{
Upregulation of tumor necrosis factor receptor- associated factor 6 correlated with synovitis severity in rheumatoid arthritis
}

Lang-Jing Zhu' ${ }^{1}$, Lie Dai ${ }^{1 *}$, Dong-Hui Zheng ${ }^{1}$, Ying-Qian Mo ${ }^{1}$, Xia Ou-Yang ${ }^{1}$, Xiu-Ning Wei ${ }^{1}$, Jun Shen ${ }^{2}$ and Bai-Yu Zhang ${ }^{1}$

\begin{abstract}
Introduction: Rheumatoid arthritis (RA) is a chronic inflammatory disease leading to joint destruction and disability. Focal bone erosion is due to excess bone resorption of osteoclasts. Tumor necrosis factor receptor-associated factor 6 (TRAF6) is one of the critical mediators both in inflammatory signal pathway and differentiation and resorption activity of osteoclasts. Here we aimed to investigate TRAF6 expression in RA synovium and its correlation with histological synovitis severity and radiological joint destruction in RA.
\end{abstract}

Methods: Synovitis score was determined in needle biopsied synovium from 44 patients with active RA. Synovium from nine patients with osteoarthritis (OA) and seven with orthopedic arthropathies (Orth.A) were enrolled as "less inflamed" disease controls. Serial sections were stained immunohistochemically for TRAF6 as well as CD68 (macrophage), CD3 (T cell), CD20 (B cell), CD38 (plasmocyte), CD79a (B lineage cells from pre-B cell to plasmocyte stage), and CD34 (endothelial cell). Double immunofluorescence staining of TRAF6 and CD68 were tested. Densities of positive staining cells were determined and correlated with histological disease activity (synovitis score) and radiographic joint destruction (Sharp score).

Results: TRAF6 expression was found in the intimal and subintimal area of RA synovium, with intense staining found in the endochylema and nucleus of intimal synoviocytes and subintimal inflammatory cells. Double immunofluorescence staining showed TRAF6 was expressed in most of the intimal cells and obviously expressed in CD68+ cells and some other CD68- cells in subintimal area. Synovial TRAF6 was significantly over-expressed in the RA group compared with the OA and Orth.A group ( $2.53 \pm 0.94$ vs. $0.72 \pm 0.44$ and $0.71 \pm 0.49, P<0.0001)$. Synovial TRAF6 expression in RA correlated significantly with synovitis score $(r=0.412, P=0.006)$, as well as the inflammatory cell infiltration $(r=0.367, P=0.014)$. Significant correlation was detected between synovial TRAF6 expression and intimal CD68+ cells, as well as the cell density of subintimal CD68+ cells, CD3+ cells, CD20+ cells, CD38+ cells, and CD79a+ cells (all $P<0.05$ ).

Conclusions: Elevated synovial TRAF6 expression correlated with synovitis severity and CD68+ cell density in RA. It is, therefore, hypothesized that synovial TRAF6 is involved in the pathogenesis of synovial inflammation and osteoclast differentiation in RA.

\footnotetext{
* Correspondence: dailie2002@21cn.com

'Department of Rheumatology, Sun Yat-Sen Memorial Hospital, Sun Yat-Sen

University, Guangzhou, 510120, P.R China

Full list of author information is available at the end of the article
} 


\section{Introduction}

Rheumatoid arthritis (RA) is a chronic autoimmune disease characterized by chronic inflammatory synovitis, leading to invasion of synovial tissue into the adjacent cartilage matrix with degradation of articular cartilage and bone, which constitutes a major cause of progressive disability and crippling of RA patients [1]. Persistent synovial inflammation is one of the most characteristic features of RA, which leads to cartilage and bone destruction, and subsequent disability in RA [2-4]. The pathogenesis of RA is complex and encompasses many cell types, including $\mathrm{T}$ cells, B cells, monocytes/macrophages and fibroblast-like synoviocytes (FLSs); each has been proved to play distinct, complex and interrelated roles in the pathogenesis and progression of RA $[5,6]$. Our previous study found synovial infiltration with CD79a+ B cells, but not other B cell lineage, correlated with synovitis score and joint destruction in RA, which indicated synovial CD79a+ B cells may be a helpful biomarker for histologic disease activity and involved in the pathogenesis of joint destruction in RA [7]. However, the related mechanism was not clear. Recent study showed that increased osteoclast formation and activity contributes to local and systemic abnormalities of bone remodeling, including bone erosion as well as focal and systemic osteoporosis [8]. Several studies have shown that osteoclast precursors and mature osteoclasts were abundant at sites of arthritic bone erosion $[9,10]$.

A tumor necrosis factor (TNF)-family molecule receptor activator of nuclear factor $\kappa \mathrm{B}$ (RANK) ligand (RANKL), and its receptor RANK, are known as the major regulators for the differentiation and activation of osteoclasts $[11,12]$. It has been shown that both RANKL and RANK were expressed on cells of RA synovium [13]. Signaling occurs following the association of RANK and RANKL primarily through tumor necrosis factor receptor-associated factor 6 (TRAF6), which influences the differentiation of osteoclasts through several pathways, including nuclear factor $\kappa \mathrm{B}(\mathrm{NF}-\kappa \mathrm{B})$ and mitogen-activated protein (MAP) kinases [14]. TRAF6 seems to be critical for RANK signaling in osteoclasts since genetical deficiency of TRAF6 resulted in compromised differentiation and defective activation of osteoclasts [15]. Furthermore, results from reconstitution experiments where $\mathrm{rank}^{-1-}$ cells were manipulated to express RANK mutants lacking the TRAF6-binding region provided evidence for the involvement of TRAF6 in RANK-directed cytoskeletal organization and resorption function of osteoclasts [16].

TRAF6 is a member of the group of seven closely related TRAF proteins, which serve as an adapter coupling the TNF receptor (TNFR) superfamily to intracellular signaling events. Moreover, TRAF6 is unique for signaling downstream of another receptor family, the interleukin-1 (IL-1) receptor/Toll-like receptor (IL-1R/ TLR) superfamily, which plays critical roles in inflammation, innate and adaptive immune responses [16]. TRAF6 has been proved as a key adapter in regulating various signaling pathways of inflammatory response and a diverse array of physiological processes, including adaptive immunity, innate immunity and bone metabolism, as well as development of several tissues including lymph nodes, mammary glands, skin and central nervous system $[17,18]$.

RA is one of the most severe chronic joint diseases by virtue of persistent synovial inflammation and destruction of cartilage and bone. TRAF6 is critical for inflammatory signaling pathways, as well as RANK signaling in differentiation and activation of osteoclasts. It has been reported that TRAF6 was up-regulated in basal RA-FLS compared to osteoarthritis (OA)-FLS, and lipopolysaccharide (LPS) stimulation could induce the up-regulation of TRAF6 in RA-FLS [19]. To date, TRAF6 expression in RA synovium has not been examined. The pathophysiological role of TRAF6 in RA has been poorly understood and whether TRAF6 is the linkage of CD79a $+\mathrm{B}$ cells and inflammation/joint destruction in RA has not been clarified. Therefore, we examined TRAF6 expression in RA synovium and analyzed its correlation with clinical disease activity, histological synovitis severity and radiological joint destruction.

\section{Materials and methods \\ Patients}

Forty-four Chinese RA patients, who fulfilled the American College of Rheumatology (ACR) 1987 criteria for RA [20], or the 2010 RA classification criteria [21], were recruited from the Department of Rheumatology of Sun Yat-Sen Memorial Hospital, Sun Yat-Sen University in Guangzhou, P.R China. All patients had active disease, defined as a Disease Activity Score 28-joint assessment $($ DAS28) $>3.2$. Eleven of them were newly diagnosed and were naïve to any treatment with prednisone or disease modifying antirheumatic drugs (DMARDs). Synovium from nine patients with $\mathrm{OA}$ as defined according to established clinical criteria, and seven with orthopedic arthropathies (Orth.A, consisting of femur fracture $(n=$ $1)$, meniscus injury $(n=3)$, meniscus cyst $(n=1)$, obsolete knee joint injury $(n=1)$, and plica syndrome of the knee joint $(n=1))$ were recruited from the Department of Orthopedics as "less inflamed" disease control [22]. The demographic and drug treatment data of the RA patients are shown in Table 1. All participants provided informed consent. The study was approved by the ethic committee of Sun Yat-Sen Memorial Hospital, Sun YatSen University, and was performed in accordance with the Helsinki Declaration. 
Table 1 Baseline characteristics of the 44 RA patients ${ }^{\star}$

\begin{tabular}{|c|c|}
\hline & RA $(n=44)$ \\
\hline \multicolumn{2}{|l|}{ Demographic characteristics } \\
\hline Age, years, median (range) & $51(23$ to 75$)$ \\
\hline Female, n (\%) & $34(81)$ \\
\hline \multicolumn{2}{|l|}{ Disease status } \\
\hline Disease duration, months, median (range) & 36 (1 to 480$)$ \\
\hline RF positive, $n(\%)$ & $35(80)$ \\
\hline ACPA positive, $\mathrm{n}(\%)$ & $37(84)$ \\
\hline DAS28, median (range) & 5.84 (3.22 to 7.92$)$ \\
\hline Synovitis score ${ }^{\Delta}$, median (range) & $4(1$ to 6.5$)$ \\
\hline \multicolumn{2}{|l|}{ Medications } \\
\hline Corticosteroids, n. (\%) & $27(61)$ \\
\hline Methotrexate, n (\%) & $16(36)$ \\
\hline Leflunomide, n (\%) & $10(23)$ \\
\hline Sulfasalazine, n (\%) & $2(5)$ \\
\hline Hydroxychloroquine, n (\%) & $1(2)$ \\
\hline Etanercept, n (\%) & $3(7)$ \\
\hline
\end{tabular}

- ACPA, anti-cyclic citrullinated peptide antibody; DAS28, Disease Activity Score 28-joint assessment; $n$, number of patients; RA, rheumatoid arthritis; RF, rheumatoid factor; SD, standard deviation.

$\Delta$ Synovitis score according to Krenn et al. [19,22,23], based on the following basic morphological parameters of synovitis: (a) hyperplasia of intima; (b) cellular density of synovial stroma and (c) inflammatory cell infiltration, including fibroblasts, endothelial cells, histiocytes, macrophages, and multinucleated giant cells. All parameters are graded from 0 (absent), 1 (slight), 2 (moderate) to 3 (strongly positive). The values of all parameters are summarized, resulting in a final score between 0 and 9 [22].

\section{Synovitis assessment}

Synovium from inflamed knees of the recruited RA patients was collected by closed Parker-Pearson needle biopsy [23]. At least six pieces of synovial tissues were obtained per patient to minimize sampling error [24]. The OA and Orth.A specimens were obtained by knee arthroplasty or arthroscopy. Samples were fixed in $10 \%$ neutral formalin, embedded in paraffin, cut in microsections of $5 \mu \mathrm{m}$ and stained with hematoxylin and eosin (H\&E) according to routine procedures.

Only tissue pieces containing synovial intima and vascularized subintima were included in the analyses. At least three such pieces were evaluated for each specimen. Histologic changes in H\&E-stained sections were graded by two observers (L-J Zhu and Y-Q Mo) according to a previously validated synovitis score $[22,25,26]$, with the modification that the average of all fields containing synovial intima was recorded per specimen.

Three features of chronic synovitis (hyperplasia of intima, cellular density of synovial stroma, inflammatory cell infiltration) were scored from 0 to 3 , with the sum providing the synovitis score, which was interpreted as follows: 0 to 1 , no synovitis; 2 to 4 , low-grade synovitis; 5 to 9 , high-grade synovitis. This score correlates positively with synovial proliferation and expression of the CD68 antigen, a well established synovial tissue biomarker for RA [22].

\section{Immunohistochemistry}

Serial sections (5 $\mu \mathrm{m}$ thickness) from paraffin blocks were stained by commercial antibody preparations according to standard staining protocols in a three-step immunoperoxidase method. Rabbit anti-human TRAF6 monoclonal antibody (mAb) (EP591Y, Abcam plc. Cambridge Science Park, Cambridge, UK) (concentration of the stock solution is not stated), mouse monoclonal antibodies (Invitrogen Corporation, San Diego, CA, USA) of CD68 (macrophages; clone KP-1, concentration of the stock solution is $0.04 \mathrm{mg} / \mathrm{ml}$ ), CD3 ( $\mathrm{T}$ cells; clone PS1, concentration of the stock solution is $0.2 \mathrm{mg} / \mathrm{ml}$ ), CD20 (B cells; clone L26, concentration of the stock solution is $0.1 \mathrm{mg} / \mathrm{ml}$ ), CD38 (plasma cells; clone SPC32, concentration of the stock solution is not stated), and CD34 (vascular endothelial cells; clone QBEnd/10, concentration of the stock solution is not stated), as well as rabbit monoclonal antibody of CD79a (B lineage cells from pre-B cell to plasmocyte stage; clone SP18, concentration of the stock solution is not stated) were used. Sections were deparaffinized with xylene, ethanol and demineralized water. Antigens were then retrieved by boiling in $1 \mathrm{mM}$ EDTA ( $\mathrm{pH}$ 8.0) for 15 to approximately 20 minutes. After the sections had been washed in demineralized water and phosphate buffered saline (PBS), the primary antibody diluted properly (TRAF6 at a 1/50 dilution, CD68 at a 1/200 dilution, CD3 at a $1 / 50$ dilution, CD20 at a $1 / 40$ dilution, CD38 at a $1 / 50$ dilution, CD34 at a 1/100 dilution, and CD79a at a 1/100 dilution) was added and incubated overnight at $4^{\circ} \mathrm{C}$. After washing with $\mathrm{PBS}$, the sections were incubated with EnVision Mouse or Rabbit conjugate (Dako Corporation, Carpinteria, California, USA) for 15 minutes at $37^{\circ} \mathrm{C}$. The color reaction was completed with the $\mathrm{DAB}+$ substrate. Sections were counterstained with hematoxylin. Nonspecific isotype IgG was used as a negative control. Absence of staining due to technical failure was excluded by including appropriate positive control tissues in each staining run.

The densities of CD79a, CD20, CD38, CD3 and CD68 positive staining cells as well as microvascular count (MCV, confirmed by CD34+ endothelial cell) were determined by manual counting. A selection of 17 highpower field (hpf) $(400 \times)$ in the superficial subintima were examined for each specimen [27]. A 1-mm graticule was used in each hpf with its edge placed just below the intima. The measured value per hpf was converted to the value per square millimeter $\left(\mathrm{mm}^{2}\right)$ by using the conversion factor $\times 0.0625^{-1}$ [28]. Semiquantitative analysis was performed to evaluate the intensity of intimal CD68+ macrophage-like synoviocytes of RA synovium as previously described [29]. Intimal CD68+ cells were scored on a scale of 0 to 4 . A score of 0 represented no or minimal infiltration, while a score of 
4 represented intense infiltration. Synovial expression of TRAF6 was scored semi-quantitatively on a five-point scale (0: absent, $1: 1 \%$ to $25 \%, 2: 26 \%$ to $50 \%, 3: 51 \%$ to $75 \%, 4: 76 \%$ to $100 \%$ ) as described previously [30]. A synovial TRAF6 score $\leq 2$ is considered as low expression, and $>2$ as high expression. Each specimen was scored by two independent observers (L-J Zhu and Y-Q Mo) in a random order; differences between the observers were resolved by mutual agreement, the kappa statistic quantifying the agreement between them was 0.920 to 0.946 .

\section{Immunofluorescence staining}

For double immunofluorescence staining of CD68 and TRAF6, paraffin-embedded sections were deparaffinized with xylene, ethanol and demineralized water. Nonspecific binding was blocked with $5 \%$ bovine serum albumin in PBS, and then the sections were incubated overnight at $4^{\circ} \mathrm{C}$ with rabbit anti-TRAF6 $\mathrm{mAb}$ (at a $1 / 30$ dilution) or normal rabbit IgG (control), and mouse anti-CD68 $\mathrm{mAb}$ (at a 1/100 dilution). The samples were then incubated with Alexa Flour 633-conjugated goat anti-rabbit IgG and Alexa Fluor 488-conjugated goat anti-mouse IgG at a 1/1,000 dilution (Invitrogen Corporation, both of the concentrations of the stock solutions are $2 \mathrm{mg} /$ $\mathrm{ml}$ ) for one hour at room temperature. DAPI (SigmaAldrich, St. Louis, MO, USA) was subsequently used for nuclei staining for five minutes and cover slips were mounted using ProLong ${ }^{\circledR}$ Gold Antifade Reagent (P36934, Invitrogen Corporation). Images were analyzed and collected with 160 Zeiss LSM 510 Confocal Imaging System (Zeiss, Jena, Germany).

\section{Disease assessments}

The disease activity of all RA patients was assessed at the time of recruitment by DAS28-C-reactive protein (CRP), which was calculated as the following formulas [31]: DAS28-CRP $=(0.56 \times \operatorname{sqrt}(28 \mathrm{TJC})+0.28 \times \mathrm{sqrt}$ $(28$ swollen joint count $(\mathrm{SJC}))+0.36 \times \ln (\mathrm{CRP}+1)) \times$ $1.1+1.15$, where $28 \mathrm{TJC}$ represents the tender joint count of 28 joints, 28SJC represents the swollen joint count of 28 joints and CRP represents C-reactive protein. The value of DAS28-CRP between 2.6 and 3.2 is considered as low disease activity, a value between 3.2 and 5.1 as moderate activity, a value $>5.1$ as high activity, and a value $<2.6$ as remission. Disability status was reported by the patients using the Swedish version of the Stanford Health Assessment Questionnaire (HAQ) [32]. Other clinical and biological parameters were also collected: morning stiffness, gripping power, erythrocyte sedimentation rate (ESR), rheumatoid factor (RF) and anti-cyclic citrullinated peptide antibody (ACPA).

Radiographs of both hands/wrists (anteroposterior view) of each patient were obtained at the recruitment visit and the joint damage was assessed as a Sharp score $[33,34]$. Seventeen areas for erosion and 18 for joint space narrowing were assessed in each hand/wrist. The maximum erosion subscore per single joint is 5 , and the maximum joint space narrowing subscore per single joint is 4, with the sum of both subscores constituting the total Sharp score. Radiographs were scored by one experienced radiologist (J Shen), who was not aware of any clinical or histological information. In a subgroup of patients, radiographs were reassessed by the same observer within two to four weeks. The correlation between these measurements was high (intraclass correlation coefficient 0.953 to 0.977 ).

\section{Statistical analysis}

The statistical analysis was performed using SPSS for Windows 13.0 statistical software (SPSS Inc., Chicago, IL, USA). Data are presented as frequencies and percentages for categorical variables and mean \pm SD for continuous variables, unless otherwise indicated. Because the expression of TRAF6 in synovium was not distributed normally, non-parametric testing using the Mann-Whitney rank sum test between two groups, or Kruskal-Wallis one way analysis of variance on ranks among three or more groups for continuous variables were used. Wilcoxon Signed Ranks Test was used for assessing the difference between baseline and 12 months after treatments. For assessing the correlation between synovial expression of TRAF6 and the histological or clinical parameters, Spearman's rank order correlation test was used. All significance tests were two-tailed and were conducted at the $5 \%$ significance level.

\section{Results}

\section{Characteristics of the study patients}

Demographic and clinical characteristics of all RA patients are shown in Table 1. Age, gender or disease duration did not differ among the patients with RA, OA and Orth.A. Ten of the RA patients were male and 34 were female. The mean age was 51.5 (range 23 to 75 ) years. Mean disease duration was 80.0 (range, 1 to 480 ) months. $80 \%$ (35/44) of the RA patients had positive RF, and positive ACPA was detected in $84 \%$ (37/44) of the RA patients. All RA patients had DAS28-CRP values > 3.2, suggesting active disease. Mean DAS28-CRP score was 5.85 (range 3.22 to 7.92 ). $75 \%(33 / 44)$ of the patients were in the high activity group, 25\% (11/44) were in the moderate. A total of $25 \%(11 / 44)$ of the RA patients had never been treated with corticosteroids or DMARDs, except for Chinese herbs and/or pain-killers to relief arthralgia. A total of $27 \%(12 / 44)$ had taken corticosteroids alone before being referred to our hospital. A total of $41 \%(18 / 44)$ had taken one or more 
DMARDs, including methotrexate, leflunomide, sulfasalazine or hydroxychloroquine, while 32\% (14/44) patients were actively on DMARDs and corticosteroids. Only 7\% (3/44) had been treated with TNF- $\alpha$ blocker (etanercept). There was no washout period before synovial biopsy.

\section{Synovial expression of TRAF6 in RA, OA and Orth.A}

To explore whether synovial expression of TRAF6 was aberrant in RA patients, we determined synovial expression of TRAF6 in 44 RA patients with a blinded manner compared with 9 patients with OA and 7 with Orth.A as "less inflamed" disease control. TRAF6 expression was found in the intimal and subintimal layer of RA synovium, with intense staining found in the endochylema as well as nucleus of intimal synoviocytes and subintimal inflammatory cells (Figure 1). Double immunofluorescence staining showed TRAF6 was expressed in most of the intimal cells and obviously expressed in CD68+ cells and some other CD68- cells in the subintimal area (Figure 2). Significantly enhanced synovial expression of TRAF6 was detected from RA patients compared to those from OA or Orth.A patients $(2.53 \pm 0.94$ vs $0.72 \pm 0.44$ and $0.71 \pm 0.49, P<0.0001$ ) (Figure 3 ). There was no significant difference in synovial TRAF6 expression between OA and Orth.A patients.

In the RA group, $34.1 \%(15 / 44)$ patients showed low synovial TRAF6 expression, $65.9 \%$ (29/44) showed high synovial TRAF6 expression, and the mean (range) synovial TRAF6 expression score was 1.5 (0.0 to 2.0$)$ and 3.1 (2.0 to 4.0$)$, respectively.

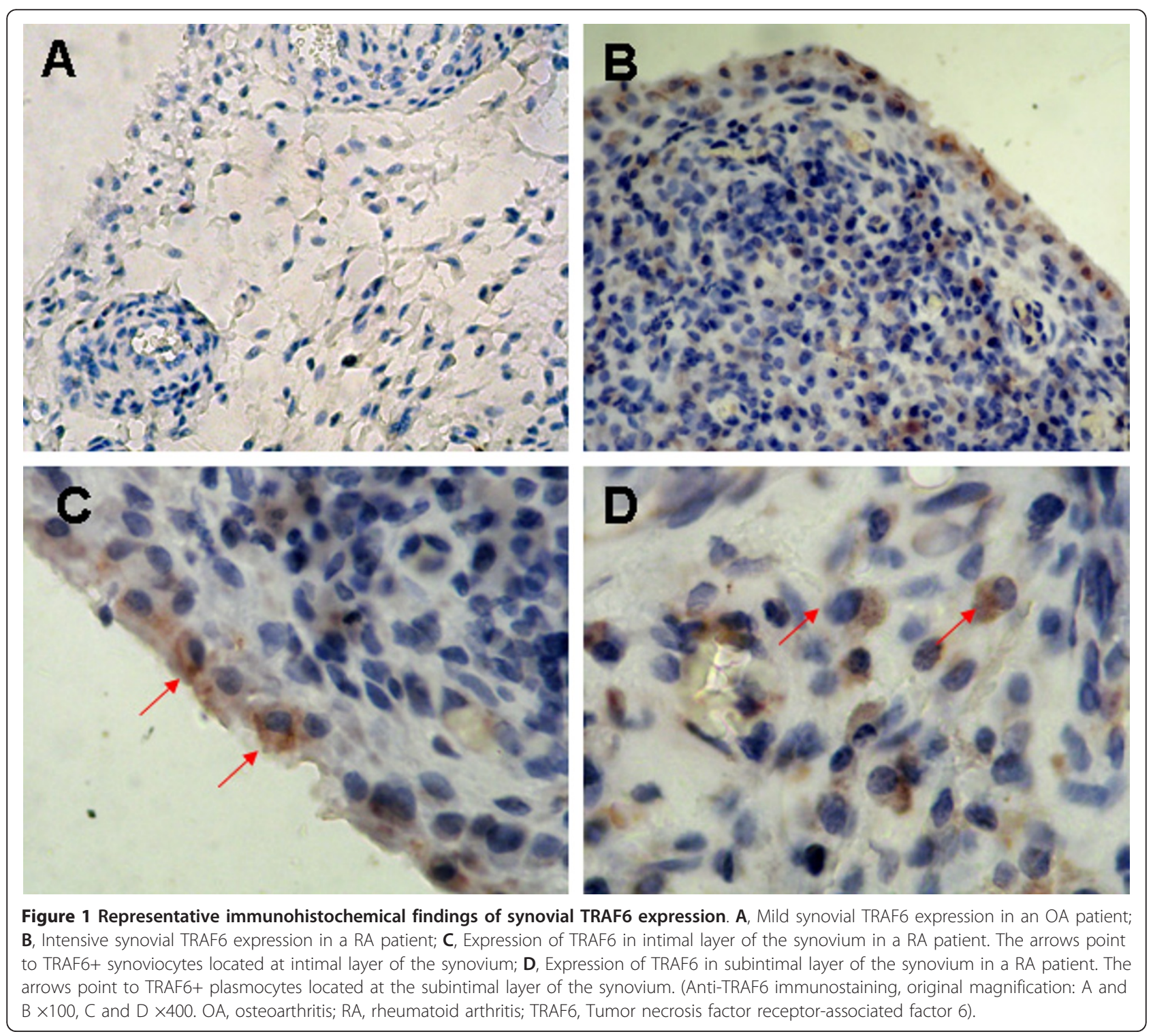




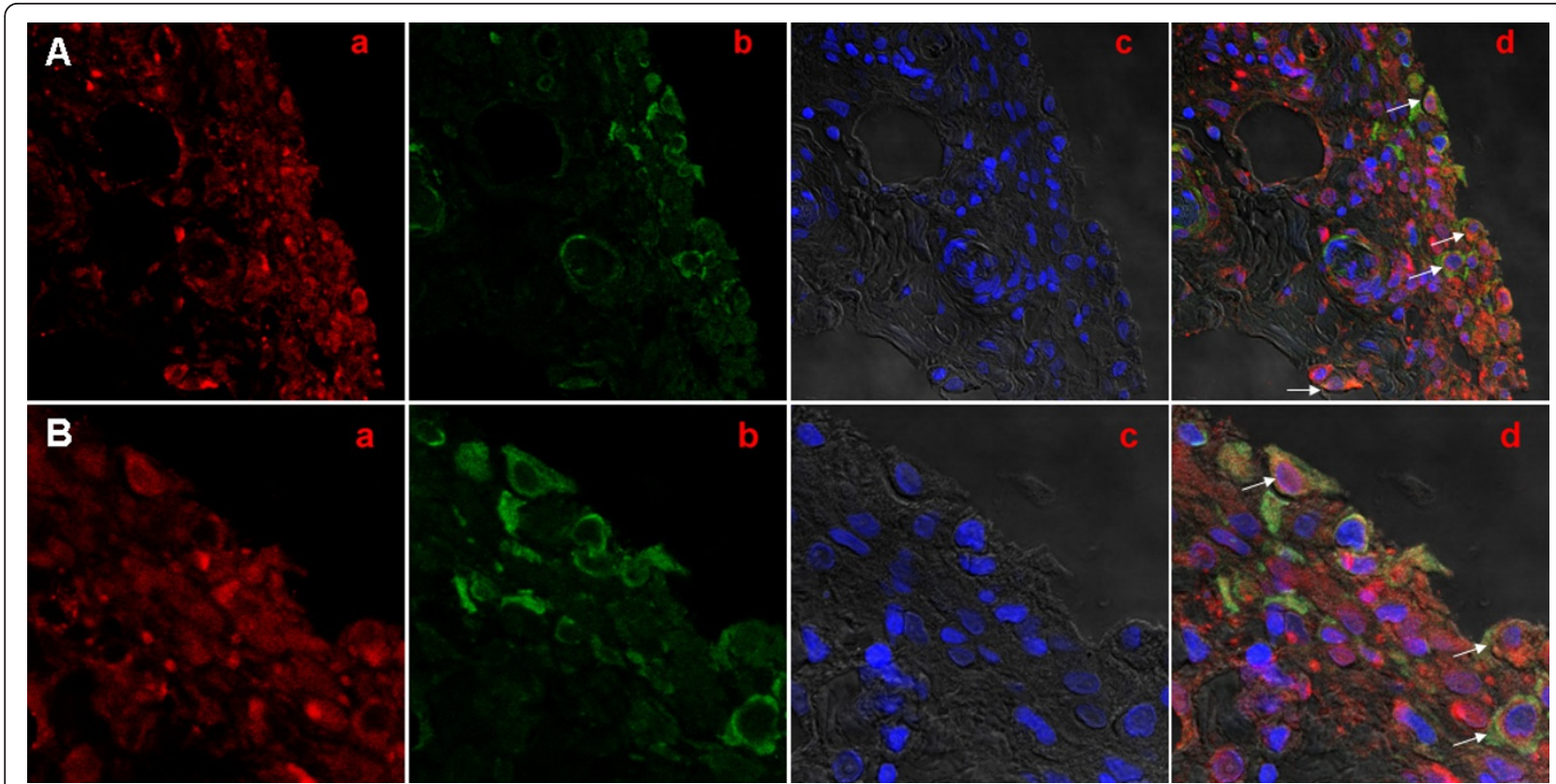

Figure 2 Representative confocal microscopic images showed TRAF6 and CD68 by indirect double immunofluorescence staining in RA synovium. A, original magnification, $\times 400$; B, original magnification $\times 1,200$. (a, TRAF6 (red); b, CD68 (green); c, DAPI (blue); d, merged a, b with c The white arrows point to intimal and subintimal CD68/TRAF6 double+ cells. DAPI, diamidino-phenyl-indole; RA, rheumatoid arthritis; TRAF6, Tumor necrosis factor receptor-associated factor 6).

\section{Correlation of synovial TRAF6 expression with the synovitis score}

Synovitis score was assessed in all 44 RA patients and the mean (range) score was 3.7 (1.0 to 6.5$)$. 63.6\% (28/ 44) patients had low-grade synovitis, $34.1 \%(15 / 44)$ had high-grade synovitis and $2.3 \%(1 / 44)$ patient had no synovitis. The mean synovial TRAF6 expression score in all RA patients was 2.5 (range 0.5 to 4.0 ). There was no significant difference in synovial TRAF6 expression between low-grade and high-grade synovitis group (2.4 \pm 1.0 vs $2.7 \pm 0.9, P=0.320)$. Moreover, synovitis score was not significantly different between low and high synovial TRAF6 expression group $(3.3 \pm 1.4$ vs $3.9 \pm 1.2$, $P=0.124)$. However, a significant correlation was found between synovial TRAF6 expression and synovitis scores from all 44 RA patients $(r=0.412, P=0.006)$ (Table 2 and Figure 4A). When the three components of synovitis score (hyperplasia of intima, cellular density of synovial stroma and inflammatory cell infiltration) were subanalyzed, the inflammatory cell infiltration was found to correlate best with synovial TRAF6 expression ( $\mathrm{r}=0.367, P=0.014$ ) (Table 2 and Figure 4B-D).

To explore the possible different effect of synovial TRAF6 expression, we subanalyzed intimal and subintimal TRAF6 expression in different grades of synovitis groups and found no significant difference in intimal or subintimal TRAF6 expression between low-grade and high-grade synovitis RA patients. Our data suggested only subintimal TRAF6 expression correlated significantly with synovitis scores $(r=0.465, P=0.001)$ and the inflammatory cell infiltration $(r=0.450, P=0.002)$ (Table 2).

Synovial TRAF6 expression correlated with the density of the common mononuclear inflammatory cells

Sequential slides from those used for TRAF6 staining were then stained for the aforementioned CD markers. In RA synovium, intimal CD68+ cells, cell density of subintimal CD68+ cells, CD3+ cells and CD34+ cells were significantly higher in the high TRAF6 expression group than that in the low TRAF6 expression group. Moreover, significant correlation of TRAF6 expression was detected with intimal CD68+ cell density $(r=0.636$, $P<0.0001)$, and subintimal CD68+ cell density ( $\mathrm{r}=$ $0.532, P=0.005), \mathrm{CD} 3+$ cell density $(\mathrm{r}=0.478, P=$ $0.004)$, CD20 + cell density $(r=0.313, P=0.047)$, CD38 + cell density $(r=0.390, P=0.020), C D 79 a+$ cell density (r $=0.398, P=0.032)$ as well as $\mathrm{MCV}(\mathrm{r}=0.596, P=$ 0.006) (Table 2).

When intimal and subintimal TRAF6 expression were subanalyzed, intimal CD68+ cells and subintimal CD3+ cell density were shown to be correlated significantly with intimal TRAF6 expression $(\mathrm{r}=0.631$ and $0.367, P$ $<0.0001$ and $P=0.033$, respectively). However, subintimal TRAF6 expression correlated significantly with subintimal CD3+ cell density $(r=0.526, P=0.001), \mathrm{CD} 20+$ 


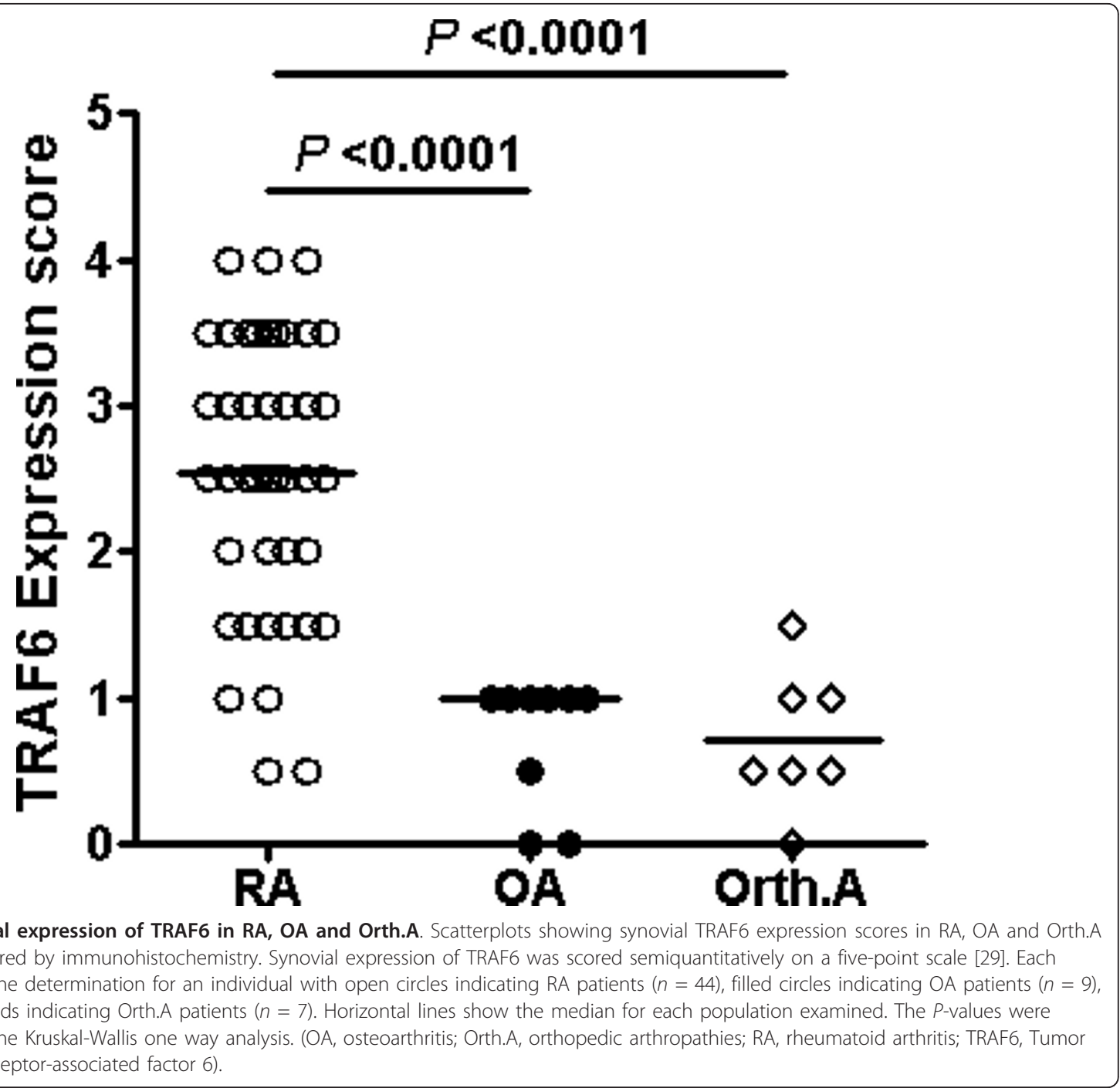

cell density $(\mathrm{r}=0.359, P=0.034), \mathrm{CD} 38+$ cell density $(\mathrm{r}$ $=0.391, P=0.020)$, CD79a + cell density $(r=0.417, P=$ $0.024)$, CD68 + cell density $(r=0.562, P=0.003)$ and $\operatorname{MCV}(\mathrm{r}=0.522, P=0.013)$, as well as intimal CD68+ cell density $(\mathrm{r}=0.604, P<0.0001)$ (Table 2$)$.

In addition, the density of subintimal common mononuclear inflammatory cell types, including CD68+ cells, CD3+ cells, CD38+ cells, CD20+ cells, and CD79a+ cells, were significantly higher in high-grade synovitis RA patients than that in low-grade synovitis RA patients. Moreover, the density of subintimal CD68+ cells, CD3+ cells, CD38+ cells, CD20+ cells and CD79a + cells correlated positively with the synovitis score $(\mathrm{r}=$ $0.306,0.539,0.635,0.752$, and 0.771 , respectively; $P=$ $0.028, P=0.001, P<0.0001, P<0.0001$, and $P<$ 0.0001 , respectively). Therefore, subintimal common mononuclear inflammatory cells may be useful indicators of histologic disease activity in RA.
Correlation of synovial TRAF6 expression with clinical parameters

Spearman's rank order correlation test was performed to investigate the correlation between synovial TRAF6 expression and ESR, CRP, RF, ACPA, TJC in 28 joints, SJC in 28 joints, HAQ, morning stiffness, gripping power or DAS28-CRP, all of which are serological or clinical parameters that reflect disease activity or severity of RA. No significant correlation was found between synovial TRAF6 expression and DAS28-CRP $(P=0.308)$ in RA. None of the above parameters correlated significantly with synovial TRAF6 expression (Table 2). No significant correlation was found between the presence/absence of synovial TRAF6 expression and age or gender or disease duration. Moreover, the above parameters were not different significantly between low TRAF6 expression group and high TRAF6 expression group. 
Table 2 Correlation between synovial TRAF6 expression and parameters of inflammation or joint destruction in RA patients

\begin{tabular}{|c|c|c|c|c|c|c|}
\hline & \multicolumn{2}{|c|}{ Intimal TRAF6 } & \multicolumn{2}{|c|}{ Subintimal TRAF6 } & \multicolumn{2}{|c|}{ Total TRAF6 } \\
\hline & $\mathbf{R}$ & $P$ & $r$ & $P$ & $r$ & $P$ \\
\hline \multicolumn{7}{|l|}{ Synovial inflammation } \\
\hline Synovitis score & 0.239 & 0.119 & 0.465 & $0.001^{* *}$ & 0.412 & $0.006^{* *}$ \\
\hline hyperplasia of intima & 0.232 & 0.130 & 0.277 & 0.068 & 0.269 & 0.077 \\
\hline Inflammatory cell infiltration & 0.164 & 0.286 & 0.450 & $0.002^{* *}$ & 0.367 & $0.014^{*}$ \\
\hline Cellular density of the synovial stroma & 0.147 & 0.340 & 0.118 & 0.444 & 0.164 & 0.288 \\
\hline CD3+ T cells & 0.367 & $0.033^{*}$ & 0.526 & $0.001 * *$ & 0.478 & $0.004^{* *}$ \\
\hline CD20+ B cell & 0.165 & 0.343 & 0.359 & $0.034^{*}$ & 0.313 & $0.047^{*}$ \\
\hline CD38+ plasma cells & 0.200 & 0.250 & 0.391 & $0.020^{*}$ & 0.390 & $0.020 * *$ \\
\hline Subintimal CD68+ cells & 0.356 & 0.074 & 0.562 & $0.003^{*}$ & 0.532 & $0.005^{* *}$ \\
\hline Intimal CD68+ cells & 0.631 & $0.000 * * *$ & 0.604 & $0.000 * * *$ & 0.636 & $0.000^{* * *}$ \\
\hline MCV & 0.578 & $0.005^{* *}$ & 0.522 & $0.013^{*}$ & 0.569 & $0.006^{* *}$ \\
\hline CD79a+ B lineage cells & 0.154 & 0.426 & 0.417 & $0.024 *$ & 0.398 & $0.032 *$ \\
\hline Disease duration & -0.161 & 0.298 & -0.144 & 0.352 & -0.145 & 0.347 \\
\hline \multicolumn{7}{|l|}{ Disease activity } \\
\hline DAS28CRP & -0.186 & 0.226 & -0.179 & 0.245 & -0.157 & 0.308 \\
\hline CRP & 0.102 & 0.513 & 0.103 & 0.510 & 0.128 & 0.413 \\
\hline ESR & -0.133 & 0.394 & -0.058 & 0.710 & -0.057 & 0.719 \\
\hline RF & -0.094 & 0.546 & -0.003 & 0.986 & 0.005 & 0.975 \\
\hline ACPA & -0.067 & 0.692 & 0.110 & 0.517 & 0.058 & 0.733 \\
\hline \multicolumn{7}{|l|}{ Joint destruction } \\
\hline Joint space narrowing subscore & -0.182 & 0.238 & -0.103 & 0.508 & -0.106 & 0.493 \\
\hline Erosion subscore & -0.233 & 0.128 & -0.125 & 0.419 & -0.145 & 0.347 \\
\hline Total Sharp score & -0.182 & 0.238 & -0.076 & 0.622 & -0.085 & 0.583 \\
\hline
\end{tabular}

Apearman's rank order correlation test was used to assess the correlation between synovial TRAF6 expression and the histological, clinical or joint destruction parameters in 44 RA patients.

ACPA, anti-cyclic citrullinated peptide antibody; DAS28, Disease Activity Score 28-joint assessment; CRP, C-reactive protein; ESR, erythrocyte sedimentation rate; $\mathrm{MCV}$, microvascular count;RA, rheumatoid arthritis; RF, rheumatoid factor; ${ }^{*} P<0.05$, ${ }^{* *} P<0.01$, *** $P<0.001$.

In addition, about $80 \%$ of RA patients in our study were positive for RF and $84 \%$ were positive for ACPA, and synovial TRAF6 expression were similar in seropositive and seronegative patients (data not shown).

\section{Correlation of synovial TRAF6 expression with joint destruction}

Unfortunately, no significant correlation was found between synovial TRAF6 expression and total Sharp score $(P=0.583)$, the erosion subscore $(P=0.347)$ or the joint space narrowing subscore $(P=0.493)$ (Table 2 ). Moreover, total Sharp score, the erosion subscore and the joint space narrowing subscore were not different significantly between low TRAF6 expression group and high TRAF6 expression group. However, disease duration correlated significantly with total Sharp score $(\mathrm{r}=0.586, P<0.0001)$, the erosion subscore $(\mathrm{r}=0.533$, $P<0.0001)$, and the joint space narrowing subscore $(\mathrm{r}=$ $0.562, P<0.0001)$. Additionally, DAS28-CRP correlated significantly with the erosion subscore $(\mathrm{r}=0.325, P=$ 0.032).
Subanalysis of treated and untreated RA patients

To exclude the influence of therapy on patient recruiting, we further subanalyzed RA patients between treated and untreated group. There was no significant difference in disease duration, age, gender or the age of disease onset between treated and untreated RA patients. There was no significant difference in clinical, serological or radiological parameters related to disease activity or severity, either. Between treated and untreated RA patients, there was no significant difference in total synovial TRAF6 expression, intimal or subintimal TRAF6 expression. But higher TRAF6 expression was found both in treated and untreated RA patients than in OA or Orth.A patients.

Four RA patients treated with methotrexate and etanercept were followed for 12 months and underwent repetitive synovium biopsy. These patients were between 30 and 51 years of age, 1 male and 3 female. Disease activity and pain decreased after 12 months compared to baseline, and synovial TRAF6 expression decreased obviously, paralleled with the decrease of synovitis score, DAS28-CRP, and Sharp score (Table 3). Wilcoxon 


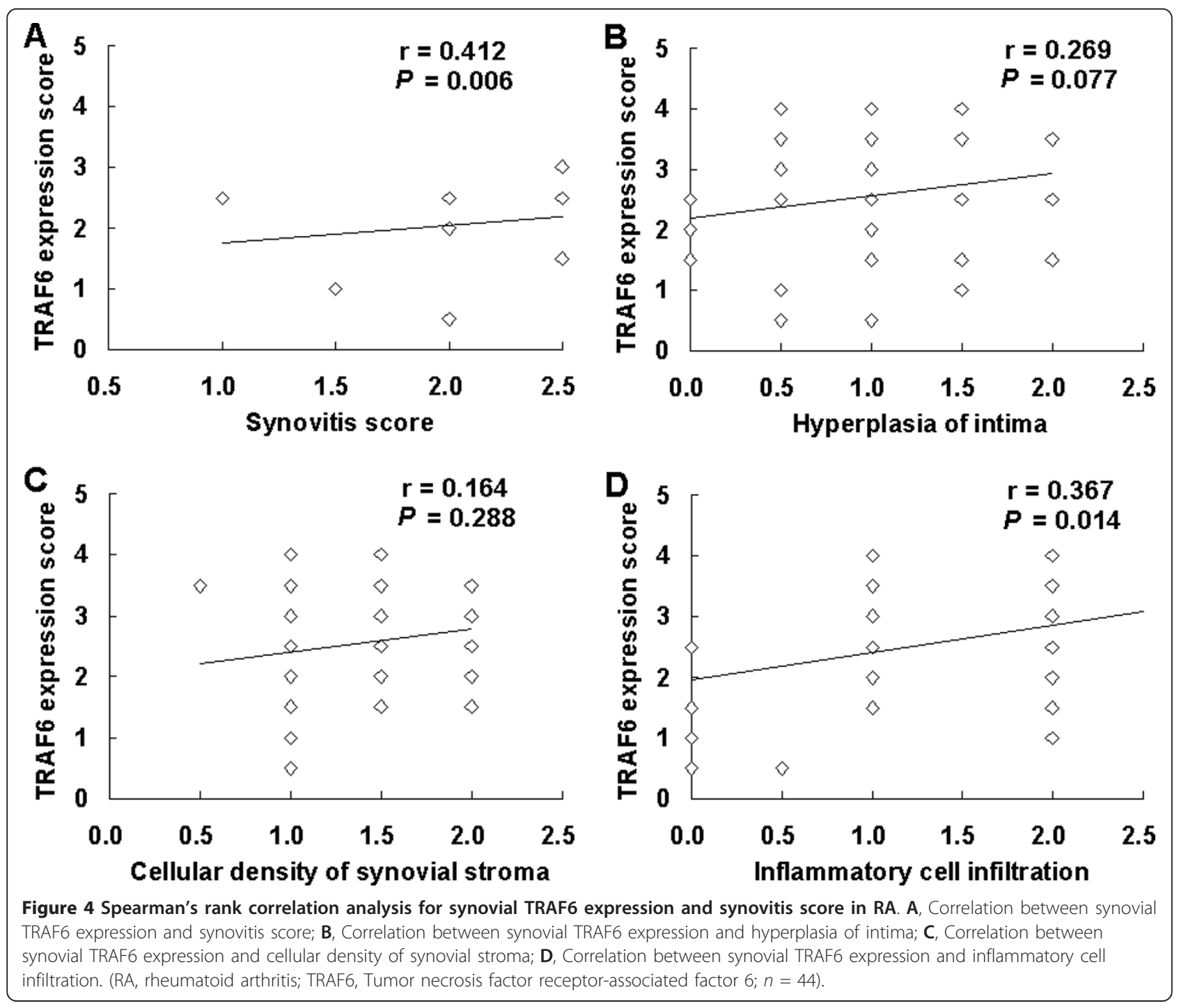

Signed Ranks Test showed the difference of DAS28-CRP and synovial TRAF6 expression between baseline and 12 months later was at borderline significance $(P=0.068$ and 0.059 , respectively). No significant difference was found in synovitis score and Sharp score between baseline and 12 months later $(P=0.257$ and 0.141 , respectively). As there were only four patients biopsied repetitively after follow up, we presumed there was actually a lack of power to detect this difference in a statistically significant manner.

\section{Discussion}

Our study showed that TRAF6 was expressed in most of the intimal cells and obviously expressed in CD68+ cells and some other CD68- cells in the subintimal area, and TRAF6 expression in RA synovium was significantly higher than that in OA or Orth.A synovium. Moreover, synovial TRAF6 expression has significant correlation with histological synovitis score and cell density of subintimal mononuclear inflammatory cells including CD3+ cells, CD38+ cells, CD20+ cells, CD68+ cells and CD79a

Table 3 Comparative analysis of synovial TRAF6 expression and disease activity in four RA patients during follow-up

\begin{tabular}{ccccc}
\hline & $\begin{array}{c}\text { DAS28-CRP } \\
\text { (mean) }\end{array}$ & Total Sharp score (mean) & $\begin{array}{c}\text { Synovitis score } \\
\text { (mean) }\end{array}$ & Synovial TRAF6 expression (mean) \\
\hline Baseline & 6.6 & 25 & 3 & 2.8 \\
12 months after treatments & 3.2 & 16 & 2 & 1.8 \\
\hline
\end{tabular}


+ cells in RA. Thus, we postulated that elevated synovial TRAF6 expression may be involved in the pathogenesis of RA synovial inflammation.

RA is a chronic inflammatory disease characterized by articular cartilage and bone destruction following growth of the inflamed synovial tissue over the articular surface. The pathogenesis of RA depends on a number of different cell types, including macrophages, which are the primary source of the proinflammatory cytokines, as well as dendritic cells, T cells, B cells, plasma cells, endothelial cells, synoviocytes and neutrophils, which produce a panoply of proinflammatory cytokines, chemokines, growth factors, matrix metalloproteinases (MMPs) and other proteolytic enzymes that degrade the articular matrix $[35,36]$. In addition, in the pathogenesis process of RA, osteoclast precursors are triggered to differentiate into mature osteoclasts, which swing the balance of normal bone turnover in favor of net resorption [37]. Our previous study [7] and the present study showed the density of subintimal mononuclear inflammatory cells correlated positively with the synovitis score, which confirmed that different cell types, especially inflammatory cells, involved in the pathophysiology of RA.

IL-1 $\beta$ and TNF- $\alpha$ play important roles in the communication among many cells in the rheumatoid joint [38]. TRAF6 functions as a common and critical signaling adapter molecule acting at the downstream of the IL1R/TLR family and TNFR superfamily [39]. TLRs have been considered to play essential roles in the pathogenesis of RA, and certain TLRs, such as TLR2, 3, 4 and 7, exhibit a high expression in RA synovium [40,41]. It is also shown that activation by endogenous TLR ligands might contribute to the persistent expression of proinflammatory cytokines by macrophages and the joint damage to cartilage and bone that occurs in RA [42]. Therefore, we suspected that TRAF6 was aberrant in RA synovium, and aimed to reveal the pathophysiological role of TRAF6 in RA. In the present study, we found intense staining of TRAF6 in the endochylema, as well as in the nucleus of intimal synoviocytes and subintimal inflammatory cells of RA synovium, which was significantly higher than that of the OA or Orth.A synovium. Additionally, synovial TRAF6 expression correlated significantly with the synovitis score and the inflammatory cell infiltration. Recruitment and retention of inflammatory cells is a fundamental process in synovitis [43]. Here we showed that the cell density of subintimal CD68+ cells, CD3+ cells and CD34+ cells in the high TRAF6 expression group of RA synovium were significantly higher than that in the low TRAF6 expression group, and synovial TRAF6 expression was correlated significantly with cell density of subintimal mononuclear inflammatory cells, including CD68+ cells, CD3+ cells,
CD38+ cells, CD20+ cells and CD79a+ cells. We then postulated that aberrant synovial TRAF6 expression may be involved in the pathogenesis of RA synovial inflammation. Ahonen $\mathrm{C}$ et al. reported TRAF6 played a very important role in triggering terminal $\mathrm{B}$ cell differentiation to plasma cells, and the loss of TRAF6 recruitment abrogated the generation of long-lived bone marrow plasma cells that secrete either low- or high-affinity nitrophenol-specific antibodies [44]. Here we also found intense staining of TRAF6 in plasma cells located at the subintimal layer of the RA synovium, which implied that TRAF6 may be involved in differentiation and antibody secretion of plasma cells in RA.

To exclude the influence of therapy on patient recruiting, we subanalyzed RA patients between treated and untreated group and no significant difference was found on all demographic and clinical parameters related to disease activity or severity. There was no significant difference on total synovial TRAF6 expression, intimal or subintimal TRAF6 expression between treated and untreated active RA patients, either. But higher TRAF6 expression was found both in treated and untreated RA patients than that in OA or Orth.A patients. Repetitive synovium biopsy was used to investigate the influence of therapy. Synovial TRAF6 expression decreased in parallel with improvement of the clinical disease activity, the histologic disease activity and radiographic joint destruction after 12 months' treatment compared to baseline, suggesting that synovial TRAF6 expression might reflect disease activity in RA.

Synovial macrophages are believed to play a crucial role in joint destruction in RA. Y. Fujikawa et al. reported synovial macrophages could differentiate into osteoclast-like cells when co-cultured with osteoblastlike UMR 106 cells, and indicated that synovial macrophages, like monocytes, were capable of altering their phenotype to that of osteoclasts when cultured under specific microenviroment [45]. Expression of CD68 is a valuable marker for identifying the monocyte/macrophage lineage cells, and CD68 is also expressed by authentic osteoclasts. Our present study showed obvious TRAF6 expression in intimal and subintimal CD68+ cells, CD68+ cell desity in the high TRAF6 expression group of RA synovium was significantly higher than that in the low TRAF6 expression group, and significant correlation was found between synovial TRAF6 expression and CD68+ cell density. Considering the well documented role of TRAF6 signaling in RANK-mediated osteoclastogenesis [15], it may, therefore, be hypothesized that TRAF6 is involved in differentiation of osteoclasts in RA.

Our previous study had found significant correlation between subintimal CD79a+ cell density and total Sharp score, the erosion subscore, as well as the joint space 
narrowing subscore in RA [7], but the underlying mechanism has not been clarified. Bone remodeling and bone loss are controlled by the RANKL-RANK- osteoprotegerin (OPG) axis. RANKL expression could be detected in inflammatory cells isolated from the synovial fluid of patients with adult or juvenile RA and patients with OA, while OPG was not detectable [46]. RANKL is the trigger of bone loss and crippling in all animal models of arthritis studied so far [47]. Recent phase II clinical trials suggested that inhibition of RANKL in human RA patients prevented bone loss at the site of inflammation without apparent effects on inflammation [48]. IL$1 \beta$ is a key link between synovitis and cartilage breakdown [49]. TRAF6 is an important signaling adapter both in the RANK-RANKL signaling pathway and IL$1 \beta /$ IL-1 receptor signaling pathway, but the role of TRAF6 in RA bone destruction is poorly understood. Here synovial TRAF6 expression in RA patients showed significant correlation with the density of CD79a+ cells, but no significant correlation with total Sharp score, the erosion subscore or the joint space narrowing subscore. We speculated that there might actually be a lack of power, with only 44 RA patients, to detect this difference in a statistically significant manner. There was likely only sufficient power to detect very strong correlations.

\section{Conclusions}

Our studies indicate that increased synovial TRAF6 expression in RA correlated significantly with histological synovitis severity and cell density of subintimal mononuclear inflammatory cells, as well as intimal CD68+ cells. It may, therefore, be hypothesized that synovial TRAF6 may be involved in the pathogenesis of RA synovial inflammation and osteoclast differentiation. TRAF6 may represent a future target for therapy of RA. A potential limitation of the present study was the lack of demonstrated expression of TRAF6 in osteoclasts or their earlier differentiation stages other than CD68+ cells; therefore, further research on subchondral tissues obtained from arthroplasty is needed. As few patients were recruited in this study, more treatment naïve RA patients and patients biopsied repetitively after treatment are needed in the future. It is worthy of further study - using TRAF6 inhibiters or siRNA silencing - to investigate the exact mechanism of how TRAF6 effect local inflammation and joint destruction in RA.

\section{Abbreviations}

ACPA: anti-cyclic citrullinated peptide antibody; CRP: C-reactive protein; DAS28: Disease Activity Score 28-joint assessment; DMARDs: diseasemodifying antirheumatic drugs; ESR: erythrocyte sedimentation rate; FLSs: fibroblast-like synoviocytes; H\&E: hematoxylin and eosin; HAQ: Health Assessment Questionnaire; hpf: high-power field; IL-1: interleukin-1; IL-1R: IL-1 receptor; LPS: lipopolysaccharide; mAb: monoclonal antibody; MAPK: mitogen-activated protein kinases; MCV: microvascular count; MMPs: matrix metalloproteinases; NF-kB: nuclear factor kB; OA: osteoarthritis; OPG: osteoprotegerin; Orth.A: orthopedic arthropathies; RA: rheumatoid arthritis; RANK: receptor activator of NF-KB; RANKL: receptor activator of NF-KB ligand; RF: rheumatoid factor; SD: standard deviation; SJC: swollen joint count; TJC: tender joint count; TLR: Toll-like receptor; TNF: tumor necrosis factor; TNFR: TNF receptor; TRAF6: tumor necrosis factor receptor-associated factor 6 .

\section{Acknowledgements}

Dr. Lang-Jing Zhu is the recipient of Chinese National Natural Science Research Grant (no. 81001334), Guangdong Natural Science Research Grant (no. 10451008901004542), Health Department Grant of Guangdong Province (no. B2010083), and the Fundamental Research Funds for the Central

Universities (no. 10ykpy19). Prof. Lie Dai is the recipient of Chinese National Natural Science Research Grant (no. 30972742).

We gratefully thank all the patients and the members of the medical staff who generously collaborated with this research, and the Key Laboratory of malignant tumor gene regulation and target therapy of Guangdong Higher Education Institutes, Sun Yat-sen University.

\section{Author details}

${ }^{1}$ Department of Rheumatology, Sun Yat-Sen Memorial Hospital, Sun Yat-Sen University, Guangzhou, 510120, P.R China. ²Department of Radiology, Sun Yat-Sen Memorial Hospital, Sun Yat-Sen University, Guangzhou, 510120, PR. China.

\section{Authors' contributions}

All authors contributed to the final manuscript. LJZ participated in the design of the study, carried out the experiments and statistical analysis, and drafted and revised the manuscript. LD designed the study, collected data, analyzed data, and drafted and critically revised the manuscript. DHZ helped with collection and acquisition of the data and the synovium, and drafted and critically revised the manuscript. YQM, XOY and XNW assisted with carrying out the experiments and collecting data, analyzed data and critically revised the manuscript. JS assisted in scoring radiographs, performed the statistical analysis and critically revised the manuscript. BYZ helped with collection of the clinical materials, analyzed data and critically revised the manuscript. All authors read and approved the final manuscript for publication.

\section{Competing interests}

The authors declare that they have no competing interests.

Received: 9 October 2011 Revised: 4 May 2012 Accepted: 4 June 2012 Published: 4 June 2012

\section{References}

1. Kamijo S, Nakajima A, Ikeda K, Aoki K, Ohya K, Akiba H, Yagita H, Okumura K: Amelioration of bone loss in collagen-induced arthritis by neutralizing anti-RANKL monoclonal antibody. Biochem Biophys Res Commun 2006, 347:124-132.

2. Tak PP: Is early rheumatoid arthritis the same disease process as late rheumatoid arthritis? Best Pract Res Clin Rheumatol 2001, 15:17-26.

3. Choy EHS, Panayi G: Cytokine pathways and joint inflammation in rheumatoid arthritis. N Eng J Med 2001, 344:907-916.

4. Kirwan JR: Links between radiological change, disability, and pathology in rheumatoid arthritis. J Rheumatol 2001, 28:881-886.

5. Wang $Q, M a ~ Y$, Liu D, Zhang L, Wei W: The roles of B cells and their interactions with fibroblast-like synoviocytes in the pathogenesis of rheumatoid arthritis. Int Arch Allergy Immunol 2011, 155:205-211.

6. Karsdal MA, Woodworth T, Henriksen K, Maksymowych WP, Genant H, Vergnaud P, Christiansen C, Schubert T, Qvist P, Schett G, Platt A, BayJensen AC: Biochemical markers of ongoing joint damage in rheumatoid arthritis - current and future applications, limitations and opportunities. Arthritis Res Ther 2011, 13:215.

7. Mo YQ, Dai L, Zheng DH, Zhu LJ, Wei XN, Pessler F, Shen J, Zhang BY: Synovial Infiltration with CD79a-positive B cells, but not other B cell lineage markers, correlates with joint destruction in rheumatoid arthritis. J Rheumatol 2011, 38:2301-2308. 
8. Schett G, Hayer S, Zwerina J, Redlich K, Smolen JS: Mechanisms of disease: the link between RANKL and arthritic bone disease. Nat Clin Pract Rheumatol 2005, 1:47-54.

9. Bromley M, Woolley DE: Chondroclasts and osteoclasts at subchondral sites of erosion in the rheumatoid joint. Arthritis Rheum 1984, 27:968-975.

10. Gravallese EM, Harada Y, Wang JT, Gorn AH, Thornhill TS, Goldring SR: Identification of cell types responsible for bone resorption in rheumatoid arthritis and juvenile rheumatoid arthritis. Am J Pathol 1998, 152:943-951.

11. Lacey DL, Timms E, Tan HL, Kelley MJ, Dunstan CR, Burgess T, Elliott R, Colombero A, Elliott G, Scully S, Hsu H, Sullivan J, Hawkins N, Davy E, Capparelli C, Eli A, Qian YX, Kaufman S, Sarosi I, Shalhoub V, Senaldi G, Guo J, Delaney J, Boyle WJ: Osteoprotegerin ligand is a cytokine that regulates osteoclast differentiation and activation. Cell 1998, 93:165-176.

12. Lum $L$, Wong BR, Josien R, Becherer JD, Erdjument-Bromage $H$, Schlöndorff J, Tempst P, Choi Y, Blobel CP: Evidence for a role of a tumor necrosis factor-alpha (TNF-alpha)-converting enzyme-like protease in shedding of TRANCE, a TNF family member involved in osteoclastogenesis and dendritic cell survival. J Biol Chem 1999, 274:13613-13618.

13. Crotti TN, Smith MD, Weedon H, Ahern MJ, Findlay DM, Kraan M, Tak PP, Haynes DR: Receptor activator NF-kappaB ligand (RANKL) expression in synovial tissue from patients with rheumatoid arthritis, spondyloarthropathy, osteoarthritis, and from normal patients: semiquantitative and quantitative analysis. Ann Rheum Dis 2002, 61:1047-1054.

14. Tolar J, Teitelbaum SL, Orchard PJ: Osteopetrosis. N Engl J Med 2004, 351:2839-2849

15. Naito A, Azuma S, Tanaka S, Miyazaki T, Takaki S, Takatsu K, Nakao K, Nakamura K, Katsuki M, Yamamoto T, Inoue J: Severe osteopetrosis, defective interleukin-1 signalling and lymph node organogenesis in TRAF6-deficient mice. Genes Cells 1999, 4:353-362.

16. Armstrong AP, Tometsko ME, Glaccum M, Sutherland $C L$, Cosman $D$, Dougall WC: A RANK/TRAF6-dependent signal transduction pathway is essential for osteoclast cytoskeletal organization and resorptive function. J Biol Chem 2002, 277:44347-44356.

17. Wu H, Arron JR: TRAF6, a molecular bridge spanning adaptive immunity, innate immunity and osteoimmunology. Bioessays 2003, 25:1096-1105.

18. Li X, Qin J: Modulation of Toll-interleukin 1 receptor mediated signaling. J Mol Med 2005, 83:258-266.

19. Arranz A, Gutiérrez-Cañas I, Carrión M, Juarranz Y, Pablos JL, Martínez C, Gomariz RP: VIP reverses the expression profiling of TLR4-stimulated signaling pathway in rheumatoid arthritis synovial fibroblasts. Mol Immunol 2008, 45:3065-3073.

20. Arnett FC, Edworthy SM, Bloch DA, McShane DJ, Fries JF, Cooper NS, Healey LA, Kaplan SR, Liang MH, Luthra HS, et al: The American Rheumatism Association 1987 revised criteria for the classification of rheumatoid arthritis. Arthritis Rheum 1988, 31:315-324.

21. Aletaha D, Neogi T, Silman AJ, Funovits J, Felson DT, Bingham CO, Birnbaum NS, Burmester GR, Bykerk VP, Cohen MD, Combe B, Costenbader KH, Dougados M, Emery P, Ferraccioli G, Hazes JM, Hobbs K, Huizinga TW, Kavanaugh A, Kay J, Kvien TK, Laing T, Mease P, Ménard HA, Moreland LW, Naden RL, Pincus T, Smolen JS, Stanislawska-Biernat E, Symmons D, et al: 2010 Rheumatoid arthritis classification criteria: an American College of Rheumatology/European League Against Rheumatism collaborative initiative. Arthritis Rheum 2010, 62:2569-2581.

22. Pessler F, Ogdie A, Diaz-Torne C, Dai L, Einhorn E, Schumacher HR: Subintimal Ki-67 as a synovial biomarker of inflammatory arthropathies. Ann Rheum Dis 2008, 67:162-167.

23. Singh JA, Arayssi T, Duray P, Schumacher HR: Immunohistochemistry of normal human knee synovium: a quantitative study. Ann Rheum Dis 2004, 63:785-790.

24. Gerlag D, Tak PP: Synovial biopsy. Best Pract Res Clin Rheumatol 2005, 19:387-400.

25. Krenn V, Morawietz L, Burmester GR, Kinne RW, Mueller-Ladner U, Muller B, Haupl T: Synovitis score: discrimination between chronic low-grade and high-grade synovitis. Histopathology 2006, 49:358-364.

26. Slansky E, Li J, Häupl T, Morawietz L, Krenn V, Pessler F: Quantitative determination of the diagnostic accuracy of the synovitis score and its components. Histopathology 2010, 57:436-443.
27. Bresnihan B, Cunnane G, Youssef P, Yanni G, Fitzgerald O, Mulherin D: Microscopic measurement of synovial membrane inflammation in rheumatoid arthritis: proposals for evaluation of tissue samples by quantitative analysis. Br J Rheumatol 1998, 37:636-642.

28. Youssef PP, Smeets TJ, Bresnihan B, Cunnane G, Fitzgerald O, Breedveld F, Tak PP: Microscopic measurement of cellular infiltration in the rheumatoid arthritis synovial membrane: a comparison of semiquantitative and quantitative analysis. Br J Rheumatol 1998, 37:1003-1007.

29. Tak PP, Smeets TJ, Daha MR, Kluin PM, Meijers KA, Brand R, Meinders AE, Breedveld FC: Analysis of the synovial cell infiltrate in early rheumatoid synovial tissue in relation to local disease activity. Arthritis Rheum 1997, 40:217-225.

30. Haynes D, Crotti T, Weedon H, Slavotinek J, Au V, Coleman M, RobertsThomson PJ, Ahern M, Smith MD: Modulation of RANKL and osteoprotegerin expression in synovial tissue from patients with rheumatoid arthritis in response to disease-modifying antirheumatic drug treatment and correlation with radiologic outcome. Arthritis Rheum 2008, 59:911-920.

31. Prevoo ML, van't Hof MA, Kuper $H H$, van Leeuwen $M A$, van de Putte $L B$, van Riel PL: Modified disease activity scores that include twenty-eightjoint counts. Development and validation in a prospective longitudinal study of patients with rheumatoid arthritis. Arthritis Rheum 1995, 38:44-48.

32. Koh ET, Seow A, Pong LY, Koh WH, Chan L, Howe HS, Lim TH, Low CK: Cross cultural adaptation and validation of the Chinese Health Assessment Questionnaire for use in rheumatoid arthritis. J Rheumatol 1998, 25:1705-1708.

33. Sharp JT, Young DY, Bluhm GB, Brook A, Brower AC, Corbett M, Decker JL, Genant HK, Gofton JP, Goodman N, et al: How many joints in the hands and wrists should be included in a score of radiologic abnormalities used to assess rheumatoid arthritis? Arthritis Rheum 1985, 28:1326-1335.

34. van der Heijde DM: How to read radiographs according to the Sharp/van der Heijde method. J Rheumotal 2000, 27:261-263.

35. Smeets TJ, Barg EC, Kraan MC, Smith MD, Breedveld FC, Tak PP: Analysis of the cell infiltrate and expression of proinflammatory cytokines and matrix metalloproteinases in arthroscopic synovial biopsies: comparison with synovial samples from patients with end stage, destructive rheumatoid arthritis. Ann Rheum Dis 2003, 62:635-638.

36. Firestein GS: Evolving concepts of rheumatoid arthritis. Nature 2003, 423:356-361.

37. Kay J, Calabrese L: The role of interleukin-1 in the pathogenesis of rheumatoid arthritis. Rheumatology (Oxford) 2004, 43(Suppl 3):iii2-iii9.

38. Proudman SM, Cleland LG, Mayrhofer G: Effects of tumor necrosis factor-a, interleukin-1 $\beta$, and activated peripheral blood mononuclear cells on the expression of adhesion molecules and recruitment of leukocytes in rheumatoid synovial xenografts in SCID mice. J Rheumatol 1999, 26:1877-1889.

39. Chung JY, Park YC, Ye H, Wu H: All TRAFs are not created equal: common and distinct molecular mechanisms of TRAF-mediated signal transduction. J Cell Sci 2002, 115:679-688.

40. O'Neill LA: Primer: Toll-like receptor signaling pathways-what do rheumatologists need to know? Nat Clin Pract Rheumatol 2008, 4:319-327.

41. Tamaki Y, Takakubo Y, Hirayama T, Konttinen YT, Goodman SB, Yamakawa M, Takagi M: Expression of Toll-like receptors and their signaling pathways in rheumatoid synovitis. J Rheumatol 2011, 38:810-820.

42. Huang QQ, Pope RM: The role of toll-like receptors in rheumatoid arthritis. Curr Rheumatol Rep 2009, 11:357-364

43. Tsubaki T, Takegawa S, Hanamoto H, Arita N, Kamogawa J, Yamamoto H, Takubo N, Nakata S, Yamada K, Yamamoto S, Yoshie O, Nose M: Accumulation of plasma cells expressing CXCR3 in the synovial subintima regions of early rheumatoid arthritis in association with production of Mig/CXCL9 by synovial fibroblasts. Clin Exp Immunol 2005, 141:363-371

44. Ahonen C, Manning E, Erickson LD, O'Connor B, Lind EF, Pullen SS, Kehry MR, Noelle RJ: The CD40-TRAF6 axis controls affinity maturation and the generation of long-lived plasma cells. Nat Immunol 2002, 3:451-456

45. Fujikawa Y, Sabokbar A, Neale S, Athanasou NA: Human osteoclast formation and bone resorption by monocytes and synovial macrophages in rheumatoid arthritis. Ann Rheum Dis 1996, 55:816-822. 
46. Kong YY, Feige U, Sarosi I, Bolon B, Tafuri A, Morony S, Capparelli C, Li J, Elliott R, McCabe S, Wong T, Campagnuolo G, Moran E, Bogoch ER, Van G, Nguyen LT, Ohashi PS, Lacey DL, Fish E, Boyle WJ, Penninger JM: Activated $T$ cells regulate bone loss and joint destruction in adjuvant arthritis through osteoprotegerin ligand. Nature 1999, 402:304-309.

47. Takayanagi H, lizuka H, Juji T, Nakagawa T, Yamamoto A, Miyazaki T, Koshihara Y, Oda H, Nakamura K, Tanaka S: Involvement of receptor activator of nuclear factor kappaB ligand/osteoclast differentiation factor in osteoclastogenesis from synoviocytes in rheumatoid arthritis. Arthritis Rheum 2000, 43:259-269.

48. Cohen SB, Dore RK, Lane NE, Ory PA, Peterfy CG, Sharp JT, van der Heijde D, Zhou L, Tsuji W, Newmark R: Denosumab Rheumatoid Arthritis Study Group: Denosumab treatment effects on structural damage, bone mineral density, and bone turnover in rheumatoid arthritis: A twelvemonth, multicenter, randomized, double-blind, placebo-controlled, phase II clinical trial. Arthritis Rheum 2008, 58:1299-1309.

49. Shiozawa S, Tsumiyama K, Yoshida K, Hashiramoto A: Pathogenesis of joint destruction in rheumatoid arthritis. Arch Immunol Ther Exp (Warsz) 2011, 59:89-95.

doi:10.1186/ar3866

Cite this article as: Zhu et al:: Upregulation of tumor necrosis factor receptor-associated factor 6 correlated with synovitis severity in

rheumatoid arthritis. Arthritis Research \& Therapy 2012 14:R133.

\section{Submit your next manuscript to BioMed Central} and take full advantage of:

- Convenient online submission

- Thorough peer review

- No space constraints or color figure charges

- Immediate publication on acceptance

- Inclusion in PubMed, CAS, Scopus and Google Scholar

- Research which is freely available for redistribution

Submit your manuscript at www.biomedcentral.com/submit 